\title{
Energy efficiency: Economics and
} Policy 


\title{
Energy efficiency: Economics and Policy
}

Pedro Linares (Universidad Pontificia Comillas and Economics for Energy, Spain) Xavier Labandeira* (Universidade de Vigo and Economics for Energy, Spain)

\begin{abstract}
Energy efficiency and conservation are major factors in the reduction of environmental impact of the energy sector, particularly with regard to climate change. Energy efficiency also contributes to reducing external dependence and vulnerabilities in the energy domain. In this paper we discuss the factors that influence energy efficiency and conservation decisions, and the most appropriate policies for their promotion. Although not all public policies seem justified, we argue that specific policies for promoting energy conservation may be required, preferably based on economic instruments or on the provision of information to consumers.
\end{abstract}

Keywords: Energy efficiency, energy, environment, public policy

JEL codes: Q41, Q54, Q48

* Corresponding author: Facultade de CC. Económicas, Campus As Lagoas, 36310 Vigo, Spain. Telephone: +34986812518, Fax: +34986812401, Email: xavier@uvigo.es. 


\section{Introduction}

In these times of economic, energy and environmental crisis, Energy Conservation and Efficiency (ECE) forms a major option from the energy sector to stand up to these challenges. We define Energy Conservation as the absolute reduction in energy demand compared to a certain baseline, measured in energy units, whereas Energy Efficiency is defined as the improvement (increase) in the efficiency with which energy is used to provide a certain product or service, measured in units of output per energy unit. Energy conservation allows us to save our scarce economic resources, postpone the depletion of our limited fossil resources (on which our current energy supply mostly depends) and, finally, is considered as one of the better alternatives for reducing carbon dioxide $\left(\mathrm{CO}_{2}\right)$ emissions. The key for the existence of all these benefits resides on the fact that people do not consume energy, but rather energy services: therefore, it may be possible to provide the same level of energy service with a lower consumption of energy.

Although energy conservation is not central to solving all our environmental problems, its contribution to some of them, like climate change, may be highly significant. To check the validity of this assertion it is only necessary to look at the parallelism between energy consumption and carbon emissions in advanced countries, as shown in Figure 1 for the US.

\section{(Figure, 1 here)}

Although this figure is included here just for illustrative purposes, a broader discussion on the statistical and causal relationship between energy demand and carbon emissions may be found at Schipper et al (1997), Ang (1999), Roca and Alcántara (2001) or Zhou and Ang (2008). This relationship depicts energy conservation as the alternative with the largest potential and cost-effectiveness to mitigate $\mathrm{CO}_{2}$ emissions. Indeed, the Intergovernmental Panel on Climate Change, in its Fourth Assessment Report (IPCC, 2007), estimates that 7 to $14 \%$ of the global greenhouse gas (GHG) emissions might be saved with negative cost measures, most of which include ECE. The International Energy Agency (IEA, 2008) also considers that ECE should provide $43 \%$ of the emissions reduction envisaged in their BLUE scenario (which sets the objective of reducing GHG emissions by $50 \%$ for 2050 ). 
In the European Union, the political support for energy efficiency (EE) is even stronger. In recent times, the Union has expressed its position in the Green Paper on Energy Efficiency "Doing more with less" (EC, 2005), in the Green Paper on Energy "A European strategy for a reliable, competitive and sustainable energy supply" (EC, 2006a), in the Action Plan for Energy Efficiency (EC, 2006b), or on the many proposals related to the Climate Action program (EC, 2008), in which EE plays a major role, again related to the EU objectives on climate change.

However, attempts at energy conservation have not been very successful and energy demand grows unchecked in most countries. It has to be said, though, that energy intensity (energy units per unit of GDP, somehow the reverse of energy efficiency) has decreased in many countries. This decrease, sometimes justified on the "dematerialization" of the economies of these countries (e.g., Medlock, 2004), has allowed to decouple to a certain extent GDP growth from the growth of energy demand, although there may be other explaining factors. Richmond and Kaufmann (2006), for example, argue that the inclusion of energy prices explains the evolution of energy intensity in most countries, so that the dematerialization hypothesis should be rejected when prices are considered. This view of the role of energy prices, which partly drive greater efficiency of processes and structural shifts, is supported by the recent work of Metcalf (2008) and Sue Wing (2008), although these papers come to different conclusions, with the former suggesting a major role for energy efficiency and the latter underscoring the role of structural shifts.

What are the explanations for the continuous increase in global energy demand despite the seemingly large economic and environmental benefits to be derived from ECE actions and the political support behind them, and also despite the improvements in energy efficiency? What are the reasons for such an apparent paradox? What should be done, if anything, to change this trend? The purpose of this paper is to reflect on these issues. It does not try to justify the need to promote energy efficiency as such, as do the institutions already mentioned, nor to become a guide for action, like the EU Action Plan. Its objective is to present a critical analysis of the questions posed, as a contribution to the current debate and to the definition of future policies. 
The article is structured in five sections, including this introduction. Section 2 analyzes the already mentioned energy efficiency paradox, while section 3 presents some ideas about the elements to be included in public policies. Finally, section 4 offers some recommendations on the general guidelines that could be followed in the future.

\section{Energy efficiency paradoxes}

At least on the surface, there are two main paradoxes surrounding energy efficiency. The first paradox relates to the fact that ECE measures have not been widely implemented despite their apparently large socio-economic benefits. The second paradox is linked to the growth of total energy consumption despite the large improvements in energy efficiency (and we are not talking here of economic growth swamping increases in energy efficiency, which certainly is not a paradox). We address these paradoxical issues in the following sub-sections under their most common denominations: the energy efficiency gap and the rebound effect.

\subsection{The energy efficiency gap}

The so-called energy efficiency paradox (or energy efficiency gap) is the fact that, although ECE seem to present clear economic and environmental advantages, the level of investment in them does not reach the levels which would correspond to such benefits. The major benefits of energy efficiency, as usually cited, would be the decrease in the amount of energy resources needed to provide a certain level of energy service, with the corresponding implications on resource depletion, energy security, and monetary savings; and the reduction in carbon emissions, other pollutant emissions, and in general terms, the environmental impact related to energy use.

In this sense, a recent study by McKinsey (2007) estimates a potential for reducing energy demand growth by $50 \%$ in the next 15 years at competitive costs. Indeed, this would reflect a largely untapped, low-cost potential that would not exist with adequate investments in ECE. However, as the reasons for not investing in efficiency and conservation are not clear, it is not evident what the real potential is. This, in turn, implies that it is not clear what the appropriate policies to promote ECE are. 
There are basically two extreme positions, with their obvious middle points, that try to explain the reasons for not investing as expected in ECE, exemplified by the classic debate between Paul Joskow and Amory Lovins in The Electricity Journal (Joskow, 1994; Lovins, 1994), or in the Special Issue of Energy Policy on this subject (Huntington et al, 1994).

On the one hand, some researchers argue that the so-called energy efficiency paradox is not such: the investments that actually take place are economically optimal, given that (some exceptions aside) energy markets are efficient. Therefore, if there is less investment than expected on ECE this is explained by decisions based on the economic rationality of consumers. In this sense, the divergence with the estimated technological potentials would be mostly explained by not accounting for the consumer behavior (see e.g. Metcalf and Hassett, 1999). In addition, it is usually argued that technological potential studies usually underestimate costs and overestimate benefits because they have been generally carried out by partial institutions or agents (Joskow, 1994).

On the other hand, other authors indicate that energy markets are full of failures that would explain the energy efficiency gap (a good illustration of these arguments is presented in Koomey and Sanstad, 1994). Indeed, some studies show that consumers' willingness to pay for improvements in ECE is larger than its cost, but then they are not carried out (see e.g. Banfi et al, 2008). This may indicate that there are market problems that prevent ECE reaching an efficient level.

Most possibly, the truth resides in a middle point: low investment in ECE is likely to be related to market failures, but also to a lack of consideration of behavioral aspects. Before getting into a more detailed analysis of those issues, though, it seems appropriate to deal with one of the most commonly argued reasons that influences non-optimal investment decisions on ECE: the high discount rates shown by some consumers when confronted with this issue. Indeed, Train (1985) reviewed the discount rates found in several studies and found values up to $90 \%$, clearly above market interest rates. Yet it should be reminded that these high discount rates are not values expressed by consumers, but rather implicit rates, and so they do not constitute a market failure by themselves, nor should they be used as an explanation of the behavior of consumers (Jaffe et al, 2004), because they do not exist as such. Instead, they could be indicators of other market failures or barriers subjacent to the decision-making process of 
consumers. Therefore, high implicit discount rates do not necessarily involve a need for a public intervention if they are due to factors other than market failures or barriers (Hausman and Joskow, 1982). In fact, high or inconsistent discount rates are not specific of energy markets, as shown for example by Laibson (1997).

The literature has pointed out and explored different reasons that may explain a lower than expected investment in ECE. Next we present a summary of the main findings regarding this issue. Table 1 summarizes all the reasons presented in this section, indicating whether they may be considered market failures or not.

Low prices of energy. If energy prices are low, investments in ECE will not be profitable. This is obviously not a market failure as long as energy prices are efficient. The problem is that this is not always the case, whether it is because prices do not include all external costs [mostly environmental, but not only, see e.g. EC (1999)]; because there are subsidies (very common under regulated electricity tariffs) which keep prices artificially low, at least for some segments of the population; or because there are regulated tariffs which isolate customers from real prices and prevent them making efficient decisions (Borenstein and Holland, 2005; Joskow and Tirole, 2007).

Higher than expected investment costs. In some cases it has been observed that investment costs are higher than those expected by technological studies (Dennis, 2006). Sometimes they do not account for 'hidden' costs (e.g., a lower level of energy service, like lighting quality), or transaction costs (Joskow and Marron, 1992). Again, this should not be considered a market failure, except for transaction costs that may be reduced through institutional reforms.

Uncertainty and irreversibility of investments. ECE investments are generally irreversible, that is, it is difficult to recover the investment if deemed unnecessary or unprofitable. If we add to that the uncertainty related to energy prices, it is evident that the investment decision has to incorporate an option value that is higher the more volatile energy prices are, and that makes the investment less profitable than if this option value is not considered (Metcalf, 1994). In general terms, uncertainty and irreversibility of investments do not constitute market failures when the risk related to them is asystematic, and therefore not socially diversifiable (Awerbuch 
and Deehan, 1995). In fact, ECE measures have good risk-hedging properties, their returns being generally negatively correlated with stock returns (Metcalf, 1994).

Information failures, including asymmetric and imperfect or myopic information. It is generally understood that consumers do not have perfect information when deciding on their investments, particularly regarding future energy prices (although part of this problem relates to uncertainty) and the characteristics of ECE options. Although some authors argue that this information failure as such is not large (e.g. Baughman and Joskow, 1975), it is widely accepted that this lack of information constitutes a market failure which should be corrected.

Bounded rationality. Even having all the information, the consumer may not be able to (or be interested in) making the complex accounting required to make the best decision. This is further induced by the fact that the implications of these decisions on the consumer's budget are not generally significant as the additional cost of a more efficient appliance is usually small compared to its total cost. Therefore, the consumer relies on fuzzy rules or on previously successful behaviors, looking for the satisfactory instead of the optimum (Simon, 1955). This usually leads to placing more importance on upfront costs, creating illusions about future prices, valuing more costs (losses) than benefits (of an increased efficiency), etc. This is not a market failure but a lack of economic rationality on the part of consumers, which may have to be corrected with different measures: education, information and, possibly, some degree of 'libertarian paternalism' (Thaler and Sunstein, 2008). For example, Train (1985) observed that, when expenses are more relevant, the implicit discount rate of the consumer is closer to the rational one.

Slowness of the technology diffusion process. In prospective technology studies, the speed of diffusion of new ECE technologies is usually overstated. However, Jaffe and Stavins (1994) show that these are slow processes and that this slowness (which in turn depends on the uncertainty and heterogeneity of consumers) explains part of the energy efficiency gap. Again, this cannot be considered a market failure by itself, although promotion of innovation and technology diffusion processes may be promoted (not necessarily to cover all the gap) due to the presence of positive externalities. Moreover, it should be noted that speeding up the rate of innovation may increase the value of the option by increasing the opportunity cost (Van Soest and Bulte, 2001). 
Principal-agent problem. This market failure takes place when the agent paying for the investment is not the one who receives the benefits from it. For example, tenants are usually those who pay the monthly energy bills that, however, depend on the equipment bought by the owner of the house. This decoupling between the investment and its benefits is generally considered a market failure, related to information failures and transaction costs. And it is a relevant matter, affecting around one third of the residential demand for energy in the US (Murtishaw and Sathaye, 2006).

Imperfections in capital markets. Another reason that may explain low investments in ECE is the difficulty in the access to capital markets, which would therefore prevent their adequate financing. A possible demonstration of its existence would be the fact that lower income segments show higher implicit discount rates, probably as a consequence of the lower access to credit and less liquid capital (Train, 1985) However, there are some arguments against this (Metcalf, 1994): the additional cost of purchasing an increment in energy efficiency is minimal related to the overall cost of appliances; the cost of revolving credit is not as high as the discount rates found; and maybe lower incomes are explained by high discount rates, and not the contrary. A related issue here is capital rationing (Brown, 2004): the fact that firms impose internal limits on capital investment, even if it is optimal. This is also a pervasive issue regarding energy efficiency, and which is clearly not a market failure, but rather has more to do with bounded rationality issues.

Heterogeneity of consumers. An investment which may be profitable for some consumers may not be so for other, for example, if the use of the investment varies (Hausman, 1979), or the sensitivity to changes in prices (Reiss and White, 2005). Again, this heterogeneity is not usually accounted for in technology studies, which explains some of their divergences with real situations. It is not a market failure, but a factor to include in these analyses.

Divergence between social and private discount rates. This is a debate which exceeds the scope of this paper, since it affects all social decisions [see e.g. Baumol (1968) or Caplin and Leahey (2004)]. Therefore, as this problem arises for many other investments, the relevant question is not if this divergence is justified, but whether the social profitability of ECE measures exceeds that of alternative social investments. 


\section{(Table 1, here)}

In sum, the relevance of the market failures and barriers already described depends on the sector considered (see e.g. their detailed description in IPCC, 2007) and of the consumer type. In this sense, it is interesting to note the above-mentioned differences in the implicit discount rates across income groups (Hausman, 1979). This would indicate that market failures and barriers would affect differently the different income groups, being reasonable to assume that low income segments have less education, information and availability of credit. The distributional and policy consequences of that finding are obviously remarkable.

Anyway, we can observe that there are many reasons which explain lower investments in $E C E$, and that it is difficult to distinguish clearly between those which are market failures from those which are not. However, the understanding of these reasons is central to the design of the appropriate ECE promotion policies. Indeed, sometimes the reason for not investing in ECE is that the return to this investment is lower than assumed due to option values, hidden costs, heterogeneity, low prices, etc., none of them necessarily market failures. Therefore, a compulsory increase of ECE investments will not necessarily improve welfare: forcing somebody to invest in ECE when she/he does not want to, for instance because she/he hardly uses a certain appliance, would mean reducing welfare. In other cases, though, there are clear market failures and public intervention seems justified.

However, given that regulations are always costly and subject to imperfections (which depend, among other things, on the chosen policy instrument), public intervention is recommended only if the market failure to correct is significant enough, and if the costs of regulation are lower than the benefits of the market failure, as in standard cost-benefit analysis.

These guidelines are however only applicable in a first-best setting, in which all market failures are known and can be solved. In a more realistic second-best situation, with multiple and pervasive market failures, particularly lack of complete information, some authors (e.g., Dennis, 2006) indicate that it may be justified to go further than just removing market failures by also addressing market barriers - that is, barriers to the penetration of ECE which are not justified by market failures and whose removal cannot therefore be justified on pure efficiency 
terms, such as bounded rationality issues, or slowness of technology diffusion. Very little work has been done on this issues (see Fischer, 2008; Bennear and Stavins, 2007; or Goulder et al, 1999), and has been focused mostly on environmental policies. As before, in any case, the key lies in selecting the cost-effective policies and alternatives to attain the ECE target.

\subsection{The rebound effect}

The rebound effect denominates the situation when an improvement in energy efficiency does not bring about a proportional reduction in energy demand (or even results in an increase in that demand). It is usually measured as a percentage (or as the elasticity of energy demand with respect to energy efficiency), so that when the rebound effect is $0 \%$ the reduction in energy demand corresponds to the increase in energy efficiency, when it is larger than $0 \%$ but lower than $100 \%$ it means that there is a net reduction in energy demand, but lower than the corresponding increase in energy efficiency, and when it is larger than $100 \%$ there is a backfire effect, with the increase in energy efficiency resulting in a net increase in energy demand, thus overwhelming the savings. In other words, the rebound effect measures to some extent the difference between energy efficiency and energy conservation: the latter accounts for absolute reductions in energy demand, whereas the former is a relative measure. And the rebound effect implies that there is not a direct causal relationship between improvements in efficiency and reductions in demand.

There are three reasons for the rebound effect, which are generally used to classify its modalities:

i. Direct, or price effect. When the energy efficiency of a process or product is improved, its implicit cost (i.e., its effective price) decreases. And, if demand is price-elastic, a decrease in the energy price will result in an increase in its consumption.

ii. Indirect, or income effect. If the effective price of energy decreases (due to an improvement in energy efficiency), then the available income increases. This increased income may allow for consuming other energy-consuming products, and therefore result again in an increase in energy demand.

iii. Macroeconomic effects. When the effective prices of energy change, relative prices of the productive inputs of the economy follow suit and thus there is a change in their use (favoring, for example, those sectors more intensive in 
energy use). Furthermore, an increase in efficiency may stimulate economic growth. This implies that individual energy savings may not be translated into overall savings, but rather in an increased energy demand.

As we can see then, there are objective reasons to expect a certain rebound effect from ECE measures, In fact, energy efficiency measures have been usually criticized by ecological economists because of its impact on the economy throughput (any improvement in energy efficiency increases the use of resources). Indeed, Saunders (1992) argued for a theoretical rebound effect larger than $100 \%$ in his Khazzoom-Brookes postulate. However, the relevant issue is not the theoretical existence of the rebound effect, but its practical validity. Indeed, the rebound effect depends on the price and income elasticities (including the possible saturation of the elasticity, i.e. reaching a point where the elasticity becomes zero), on the possibility of switching between fuels, or on the productive framework of the economy.

In sum, although in theory we should always expect a certain rebound effect, its practical relevance is context dependent. The estimates from different researchers point to a wide range of values (for a good, albeit outdated, review see Greening et al, 2000). Grubb (1990), for example, argues that the impact of the rebound is negligible (between $5 \%$ and $15 \%$ of the efficiency gain, and that higher values are explained by an unaccounted substitution effect. This might be perhaps the rebound to be expected in those sectors with a reduced elasticity, such as electricity consumption, although in other sectors (e.g. transport) higher figures have been obtained, up to $67 \%$ (Frondel et al, 2008). At the macroeconomic level, significant rebound levels have also been estimated: Barker et al (2007) provided 19\% for the UK, Mizobuchi (2008) 27\% in Japan, and Hanley et al (2009) 50\% in the short term and 130\% in the long term for Scotland.

It should be reminded anyway that, when the rebound effect is lower than $100 \%$, there will always be a net reduction in energy demand and that this reduction should be compared with the scenario without ECE measures (not with the business as usual). Therefore, the rebound effect by itself is not an argument for abandoning energy efficiency, as proposed by some commentators (e.g. Herring, 2006). Another issue related to the rebound effect is that the reduction in energy demand may be costlier than expected (if the amount saved is lower, for the same cost). Finally, it is interesting to mention that the rebound effect is not bad in itself, 
since it comes as a consequence of the welfare maximization of consumers. But of course, it reduces energy savings, and therefore reduces the effectiveness of ECE policies and thus should be taken into account when designing them.

\section{Policies for energy conservation}

We have seen that there are market failures which explain, to a certain extent, the energy efficiency gap and that should be corrected. However, ECE policies should not be considered here as goals by themselves but as a means for a better allocation of scarce resources, to improve the environment or to reduce foreign dependence and vulnerability. This means that it might be more reasonable to use policies specifically directed at solving those problems. For instance, carbon pricing (through taxation or emissions trading) would correct the climate change externality and other supplementary policy would probably distort the efficient allocation of resources (e.g. Brookes, 2000). This is obviously related to the well-known Tinbergen (1952) rule to use a single instrument to tackle each problem.

Although this is valid in a first-best setting, it is difficult to imagine carbon prices high enough as to promote the emissions reductions required, or a sufficiently stable regulatory climate in which those prices may be able to internalize the externality in the long term. Under these more realistic conditions, ECE policies may still play a relevant role against climate change (Linares and Pérez-Arriaga, 2008). Hence, as already proposed by Grubb (1990), it seems that we should stop discussing the need to promote ECE policies and rather analyze which are the most efficient policies to achieve the desired improvements in a second-best scenario.

In any case, we must keep in mind that the final objective of ECE policies is to save energy: energy efficiency is only interesting if it results in net savings, that is, if the rebound effect is lower than 100\%. Secondly, policies should be as effective and efficient as possible, avoiding free-riding behavior. Finally, ECE policies must be targeted at the market failures or barriers that we want to remove. That is, we should not try to solve an information failure through fiscal policy, or an environmental externality with information campaigns. As the first point has already been addressed in the previous section, we will deal with the other two next. 


\subsection{Free-riding}

Like any other public policy, ECE policies must be efficient, that is, use resources in an optimal way. However, sometimes resources are wasted because they would not be necessary to achieve the desired reduction in energy demand. This is generally due to freeriding behavior as there would be agents that receive public funds to carry out actions that would have been implemented in the absence of these funds. Joskow and Marron (1992) found a significant amount of free-riding in their analysis of utility-based ECE programs in the US, and Hassett and Metcalf (1995) detected that most of the subsidies for energy conservation were received by households that would have invested anyway. In Germany, Grosche and Vance (2009) observed that $50 \%$ of the households which received subsidies for energy improvements were willing to pay more than the cost without subsidy, and therefore they free rode on the program. Of course, it seems desirable to design policies so that, while maintaining their beneficial effects, free-riding effects are minimized.

\subsection{ECE policy instruments}

We now describe the general characteristics of the major alternatives for correcting market failures or achieving the targets required. We do not deal with specific applications given that there is a substantial literature about them. From a theoretical point of view, for instance, Bye and Bruvoll (2008) provide a fine analysis of different ECE policies. Gibbons and Gwin (2004) provide a good historic account of the major ECE measures taken, whereas Gillingham et al (2006) carry out a retrospective analysis of the measures applied in the US. The International Energy Agency also features a large online database on ECE policies (www.iea.org). Finally, regarding future policies, the EU Action Plan (EC, 2006b) or the World Energy Council (2008) also propose a broad array of possible measures.

\subsubsection{Technological standards}

Technological standards, usually translated into minimum energy efficiency requirements for energy equipments, have been the most popular choice for ECE, possibly because of their political attractiveness. Nadel (2002) offers a good summary of the application of standards in different countries. These instruments are popular due, among other issues, to the lack of transparency of the cost for the consumer, to their effectiveness regarding efficiency (although 
not necessarily savings) and to their easy implementation. In addition, they address problems like incomplete information, bounded rationality or technology diffusion externalities, which may prove them very useful in second-best settings, as explained by Fischer (2008) or Fischer and Newell (2008) - see also the references provided for regulation under second-best settings provided before.

When standards are absolute, that is, when there is an obligation to save in energy consumption (usually ensured by a penalty), they are very effective in terms of energy conservation (Waide and Buchner, 2008). However, this is not usual because standards are generally relative (they apply to efficiency, not savings) and present many problems as described below (Hausman and Joskow, 1982). Moreover, there are some occasions in which standards are not a good choice from the start. For example, when technology advances so quickly that standards deter, rather than promote, technology change. This means that, to be effective, standards should be constantly updated, which raises the question of whether the government is the institution most suited for this task (Jaffe and Stavins, 1994).

Some other problems which may arise from the use of standards include their typical association to an increase in investment costs and a decrease in operation costs that, given the sunk character of the former, generates a large possibility for a rebound. The rebound is even larger when standards are not coupled with compulsory retirement programs, because then many customers may choose to keep also the older appliances, such as the infamous "beer fridges" in the US and Canada (Young, 2008). A second problem arises because standards increase costs for consumers, albeit in a hidden way. The studies that neglect this phenomenon compare the price of appliances before and after standards, not with the prices that would have resulted without standards. In fact, it seems difficult to believe that just setting a standard makes industries aware of the need to reduce prices or costs. It is more likely that manufacturers compensate the higher cost of the appliance with a reduction in the cost of other elements, so there is really an (implicit) opportunity cost (Nadel, 2002). Finally, setting uniform standards may also decrease welfare if there is heterogeneity among consumers (intrinsic, due to different tastes, or climatic). This might be solved by allowing agents to change the allocation of the energy saving requirements by trading among themselves (Bertoldi and Rezzesy, 2008), an issue contemplated in the next subsection. 


\subsubsection{Tradable white certificates}

Tradable white certificates (TWC) as a regulatory measure consist in first setting an absolute reduction target for energy demand, and then allowing to trade this obligation among the agents required to implement it by means of tradable certificates. They are thus quite similar to cap-and-trade schemes applied in the fields of Environmental and Resource Economics. This system is becoming quite popular because of its potential efficiency for achieving a given target (although lower than that of other instruments, as shown by Giraudet and Quirion, 2008), their political acceptability, their large degree of flexibility, or their emphasis on absolute reductions (Perrels, 2008).

Although their above-mentioned advantages make them usually preferable to standards, TWC also have some problems. For instance, the proper baseline for evaluating the real savings may be difficult to define, transaction costs may be large, and sectoral limits usually must be set (Langniss and Praetorius, 2006). Yet the experiences with these instruments in the UK, France and Italy have been quite positive (Mundaca, 2007; Pavan, 2008), although there are still practical implementation problems to be solved .

\subsubsection{Taxes}

Economists usually consider a price signal as the most powerful instrument for promoting ECE. If energy prices do not account for externalities, or do not yield enough incentives for energy efficiency, they should be raised (through taxes, for example). In fact, the induced innovation hypothesis proposes that an increase in energy prices induces technological changes which in turn allow for an increase in energy efficiency (Newell et al, 1999). This has been empirically shown by some studies, although others do not find this relationship (Sue Wing, 2008). At a global level, however, countries with higher energy prices (like Scandinavia) are those that also feature higher levels of energy efficiency. In this respect, it also seems very important the stability and expectations of high energy prices, which can be attained through taxes.

Taxes have less problems than technological standards: their costs are transparent, they are compatible with the heterogeneity of consumers, and they promote by themselves technology change. Moreover, by not reducing the effective energy price, they remove the direct rebound 
effect in the short term (although in the long term this will appear through the improvement in energy efficiency, and there may still be some indirect and macroeconomic rebound), and they do not allow for free riding. In addition, given the irreversible nature of ECE investments, the reaction to an energy price increase is stronger than the one resulting from a decrease, which again proves the usefulness of this instrument (Gately and Huntington, 2002). A final advantage of taxes is related to their revenue-raising nature, which allow the use of receipts in an efficiency-enhancing fashion (Gago and Labandeira, 2000), to mitigate negative distributional effects, or in the promotion of new technologies or behavioral changes.

However, taxes also present several shortcomings. First, if the price elasticity of energy demand is small - as widely recognized to be the case in the short term, see e.g. the surveys by Madlener (1996), Brons et al (2008) or Lijesen (2007) -, the potential of price instruments for achieving reductions in energy demand would be limited. Second, taxes are not very popular as energy price rises are always highly contested, in part due to differential impacts on the poor (regressivity) or on certain sectors and regions. Although as indicated above it is possible to combine the higher efficiency of the price instrument with a (distributional) compensatory use of revenues, the truth is that most consumers prefer carrots to sticks (Boardman, 2004).

It should be noted here that a careful analysis of the effectiveness and efficiency or taxes would require a good understanding of the demand function for energy: how the consumers respond to prices and also to other signals. This is a very extensive field of research, also one of great interest. However, getting into that topic would require lengthening this paper too much.

\subsubsection{Subsidies}

Subsidies (including direct payments and tax credits) are, in contrast, very popular both socially and politically. This may explain their extended use for ECE policies, particularly in the promotion of sales of efficient appliances. And they may be more effective for the adoption of energy-efficient technologies. In this sense, Jaffe and Stavins (1995) found that investment subsidies were three times more effective than an equivalent price increase - or, as the authors put it, that the impact of up-front technology costs was much greater than that of the longer term energy prices. Their explanation for these results was basically possible 
shortcomings of their modeling, particularly the expectation of future prices. Hassett and Metcalf (1995) also found evidence that tax credits for ECE investments were up to eight times more effective than an equivalent price increase. They explain their results based on uncertainty (about future prices) and information effects (the expectations of a subsidies program being started shortly). However, an additional explanation for this behavior, related to the uncertainty issue, may be prospect theory (Kahnemann and Tversky, 1979): under uncertainty, people prefer to avoid losses than to acquire gains. Given that an investment in energy-efficient equipment is a certain loss with uncertain gains (those resulting from avoiding higher and uncertain energy prices), reducing the loss through subsidies may be more effective than reducing the gains.

However, subsidies allow (and certainly favor) the rebound effect by reducing the effective price of energy, and also promote free-riding. Therefore, their final effectiveness and efficiency are much compromised, in spite of their apparent success under simple assessments. This has been apparently the case with utilities' subsidies programs, one of the major vehicles for ECE promotion. Joskow and Marron (1992) or Loughran and Kulick (2004) found that reductions were lower than expected and costs higher than utilities' estimates - although Auffhammer et al (2008) revised Loughran and Kulick's data and found that the utilities results could not be rejected.

In this case, another problem is related to the fact that savings targets are not usually well aligned with the interests of utilities as they result in lower sales and lower revenues. Here an interesting idea would be to decouple revenue from sales, only feasible under regulated frameworks - thus removing the negative incentive for utilities to carry out energy efficiency programs, since then these programs would not have an impact on their revenues. Another idea would be to take EE obligations from utilities - which, as said before, do not have the right incentives to do it since they would lose revenues - and allocate them to independent agencies or firms (Waide and Buchner, 2008; Munns, 2008).

\subsubsection{Information policies}

Information programs, such as energy labeling or disclosure of data, are targeted to solve the incomplete information failure and also some barriers related to bounded rationality. Although there are some authors who argue that more information by itself may not be effective, 
because the information failure is not significant (Hassett and Metcalf, 1993) or because the level of education (and information) was not relevant for investments in insulation (Brill et al, 1999), others do think that these policies are very useful and cost-effective.

For example, Boardman (2004) argues that increasing the knowledge about the consumption of appliances in stand-by reduces its use. In another study, Zografakis et al (2008) found a significant impact of education on energy savings. Reiss and White (2008) also found that informational programs and conservation appeals did reduce electricity demand in California. Of course, in order for it to be effective the level of information provided must be enough: Sanstad and Howarth (1994), for example, argue that energy labeling programs are useless if not coupled with information about prices (and therefore with total monetary savings).

\subsubsection{Combination of policies}

Although we could observe that the preceding instruments present theoretical advantages, it is also evident that all of them present drawbacks, especially concerning their practical implementation. Therefore, it may also be reasonable to use a combination of them as the most effective way to promote ECE (Metcalf, 2006). This is basically due to the fact, first of all, that the response to policies may become saturated and thus their impact mitigated. For example, Woods (2008), in his study of ECE measures applied to US residential customers, found that there is very little potential for thermostat adjustments, given that this measure is already very popular. This may, therefore, require using a different policy.

A second reason for a combination of instruments is the possible interaction between them. For instance, some policies may have an impact on price elasticities and so on the effectiveness of price instruments (Boonekamp, 2007). In this sense, Newell et al (1999) showed that, when there are associated information programs, the impact of price instruments is higher because they increase elasticity.

\section{Conclusions}

This paper has tried to reflect upon the possible contribution of ECE policies to the achievement of different socio-economic and environmental objectives. As a major point, we 
emphasized that ECE policies should be considered as means to an end, not as an end in themselves. For instance, if the objective is to improve the environment, priority should be given to policies directly targeted at a reduction of the environmental impact such as environmental taxes or quotas (tradable or not). If the goal is to improve overall efficiency, then the correction of the different market failures is the first step to take. Yet it was also stressed that, in a second-best context, these priority policies may not be enough and ECE policies may be needed even exceeding the theoretically optimal level of energy efficiency.

Therefore, if energy conservation must be higher than its "economically efficient" level resulting from the internalization of all market failures (but not removing other barriers), all ECE measures will have a cost for society which should be added to the costs associated to the policies themselves. That is, although some studies mention negative costs for energy savings, one has to be well aware that ECE policies will imply a positive cost. Of course, this does not mean that these costs should not be incurred if the overall benefits resulting from these policies compensate them, as seems to be the case for climate change or reduced energy dependence. It simply means that we should not necessarily believe in the existence of plentiful cheap and effective measures for reducing our energy demand.

Another important aspect underlined in the paper is the need to avoid mistaking efficiency and conservation (see the definition in the Introduction). Although most policies are targeted to improving the former, this does not necessarily mean achieving the latter because of the rebound effect. Therefore, the orientation of ECE policies should be modified, abandoning the idea of efficiency as an end in itself and targeting them exclusively towards real savings.

In this context, economic instruments such as taxes or TWC seem to be vastly superior to standards or subsidies. Standards may generate larger rebounds and reduce welfare compared to taxes or TWCs, and subsidies also facilitate rebounding and free-riding behavior. Information programs seem to be also necessary, as well as other instruments designed to correct the lack of rationality of the consumers (such as those based on libertarian paternalism, but also including standards if necessary). Here the point to emphasize is that different policy instruments may be required to address the different market failures and barriers that prevent a larger reduction in energy demand. Table 2 presents a summary of the 
policy instruments to be used to address each of the reasons for the energy efficiency paradox.

\section{(Table 2, here)}

As a final point, the economic analysis of the effectiveness and efficiency of ECE policies should certainly advance and become more widespread. In the US, more than a thousand studies assessing the impacts of ECE policies have been identified (Vine, 2008) but the role of economics is still limited. Only through careful evaluation will we be able to design the most appropriate policies to promote energy savings, and therefore contribute in the most efficient way to their socio-economic and environmental benefits.

\section{Acknowledgements}

We thank Xiral López-Otero, Maria Mendiluce, Ignacio Pérez-Arriaga, Gonzalo Sáenz-de-Miera and two anonymous reviewers for their suggestions. Funding from the Spanish Ministry of Education and Science (SEJ2006-12939) is also gratefully recognized. The authors are members of the FEDEAIberdrola chair on Economics of Climate Change. They are fully responsible for any remaining errors or omissions. 


\section{References}

Ang, B.W., 1999. Is the energy intensity a less useful indicator than the carbon factor in the study of climate change?. Energy Policy 27: 943-946.

Aufhammer, M., Blumstein, C. and Fowlie, M. (2008) Demand-side management and energy efficiency revisited. Energy Journal 29: 91-104.

Awerbuch, S. and Deehan, W. (1995) Do consumers discount the future correctly? A marketbased valuation of residential fuel switching. Energy Policy 23: 57-69.

Banfi, S., Farsi, M., Filippini, M., Jakob, M. (2008) Willingness to pay for energy-saving measures in residential buildings. Energy Economics 30: 503-516.

Barker, T., Ekins, P. and Foxon, T. (2007) Macroeconomic effects of efficiency policies for energy-intensive industries: The case of the UK Climate Change Agreements, 2000-2010. Energy Economics 29: 760-778.

Baughman, M. and Joskow, P. (1975) The effects of fuel prices on residential appliance choice in the United States. Land Economics 51: 41-49.

Baumol, W.J. (1958) On the social rate of discount. American Economic Review 58: 788-802.

Bennear, L.S., and Stavins, R.N. (2007). Second-best theory and the use of multiple policy instruments. Environmental and Resource Economics 37: 111-129.

Bertoldi, P. and Rezessy, S. (2008) Tradable white certificate schemes: fundamental concepts. Energy Efficiency 1: 237-255.

Boardman, B. (2004) New directions for household energy efficiency: evidence from the UK. Energy Policy 32: 1921-1933.

Boonekamp, P.G.M. (2007) Price elasticities, policy measures and actual developments in household energy consumption - A bottom up analysis for the Netherlands. Energy Economics 29: 133-157.

Borenstein, S. and S. Holland (2005). On the Efficiency of Competitive Electricity Markets with Time-Invariant Retail Prices On the Efficiency of Competitive Electricity Markets with TimeInvariant Retail Prices. The RAND Journal of Economics, 36: 469-493

Brill, A.M., Hassett, K.A. and Metcalf, G.E. (1999) Household energy conservation investment and the uninformed consumer hypothesis. Discussion Paper 99-18, Tufts University.

Brons, M., Nijkamp, P., Pels, E., Rietveld, P. (2008). A meta-analysis of the price elasticity of gasoline demand. A SUR approach. Energy Economics 30: 2105-2122.

Brookes, L. (2000) Energy efficiency fallacies revisited. Energy Policy 28: 355-366.

Brown, M.A. (2004) Obstacles to Energy Efficiency. Encyclopedia of Energy Vol. 4, Elsevier

Bye, T. and Bruvoll, A. (2008) Multiple instruments to change energy behavior: The emperor's new clothes? Energy Efficiency 1: 373-386.

Caplin, A. and Leahy, J. (2004) The social discount rate. Journal of Political Economy 112: 1257-1268

Dennis, K. (2006) The compatibility of economic theory and proactive energy efficiency policy. The Electricity Journal 19: 58-73.

EC (1999). ExternE Externalities of Energy. Multiple volumes. European Commission. 
EC (2005) Green Paper on Energy Efficiency or Doing More with Less. COM(2005)0265 final. Luxembourg: Office for Official Publications of the European Communities.

EC (2006a) Green Paper. A European Strategy for Sustainable, Competitive and Secure Energy. COM(2006)0105 final. Luxembourg: Office for Official Publications of the European Communities.

EC (2006b) Action Plan for Energy Efficiency: Realising the Potential. COM(2006)0545 final. Luxembourg: Office for Official Publications of the European Communities.

EC (2008) Climate Action. Energy for a changing world. European Commission, http://ec.europa.eu/climateaction/index_en.htm.

Fischer, C. (2008). Emissions pricing, spillovers, and public investment in environmentally friendly technologies. Energy Economics 30: 487-502.

Frondel, M., Peters, J. and Vance, C. (2008) Identifying the rebound: Evidence from a German household panel. Energy Journal 29: 145-164.

Gago, A. and Labandeira, X. (2000) Towards a green tax reform model. Journal of Environmental Policy and Planning 2: 25-37.

Gately, D. and Huntington, H. (2002) The asymmetric effects of changes in Price and income on energy and oil demand. Energy Journal 23: 19-55.

Gibbons, J.H. and Gwin, H.L. (2004) History of conservation measures for energy. Encyclopedia of Energy 1: 649-659.

Gillingham, K., Newell, R. and Palmer, K. (2006) Energy efficiency policies: A retrospective examination. Annual Review of the Environment and Resources 31: 161-192.

Giraudet, L-G. and Quirion, P. (2008) Efficiency and distributional impacts of tradable white certificates compared to taxes, subsidies and regulations. FEEM Nota di Lavoro 88.2008.

Goulder, L.H., Parry, I.W.H, Williams, R.C., Burtraw, D. (1999). The cost-effectiveness of alternative instruments for environmental protection in a second-best setting. Journal of Public Economics 72: 329-360.

Greening, L., Greene, D.L. and Difiglio, C. (2000) Energy efficiency and consumption - the rebound effect - a survey. Energy Policy 28: 389-401.

Grosche, P. and Vance, C. (2009) Willingness-to-pay for energy conservation and freeridership on subsidization: Evidence from Germany. Energy Journal 30: 135-154.

Grubb, M. (1990) Energy efficiency and economic fallacies. Energy Policy 18: 783-785.

Hanley, N., McGregor, P.G., Swales, J.K. and Turner, K. (2009) Do increases in energy efficiency improve environmental quality and sustainability? Ecological Economics 68: 692709.

Hassett, K.A. and Metcalf, G.E. (1993) Energy conservation investment. Do consumers discount the future correctly? Energy Policy 21: 710-716.

Hassett, K.A. and Metcalf, G.E. (1995) Energy tax credits and residential conservation investment: Evidence from panel data. Journal of Public Economics 57: 201-217.

Hausman, J.A. (1979) Individual discount rates and the purchase and utilization of energyusing durables. The Bell Journal of Economics 10: 33-54. 
Hausman, J.A. and Joskow, P.L. (1982) Evaluating the costs and benefits of appliance efficiency standards. American Economic Review 72: 220-225.

Herring, H. (2006). Energy efficiency - a critical view. Energy 31: 10-20.

Huntington, H., Schipper, L. and Sanstad, A.H. (1994) Markets for energy efficiency. Editor's introduction. Energy Policy 22: 795-797.

IEA (2008) Energy Technology Perspectives 2008. Scenarios and strategies to 2050. Paris: International Energy Agency.

IPCC (2007) Climate Change 2007: Synthesis Report. Contribution of Working Groups I, II and III to the Fourth Assessment Report of the Intergovernmental Panel on Climate Change [Core Writing Team, Pachauri, R.K and Reisinger, A. (eds.)]. Geneva, Switzerland.

Jaffe, A.B., Newell, R.G. and Stavins, R.N. (2004) Economics of energy efficiency. Encyclopedia of Energy 2: 79-90.

Jaffe, A.B. and Stavins, R.N. (1994) The energy paradox and the diffusion of conservation technology. Resource and Energy Economics 16: 91-122.

Jaffe, A.B., and Stavins, R.N. (1995). Dynamic incentives of environmental regulations: The effects of alternative policy instruments on technology diffusion. Journal of Environmental Economics and Management 29: S43-S63.

Joskow, P.L. (1994) More from the guru of energy efficiency: 'There must be a pony! The Electricity Journal 7: 50-61.

Joskow, P.L. and Marron, D.B. (1992) What does a negawatt really cost? Evidence from utility conservation programs. Energy Journal 13: 41-75.

Joskow, P.L. and Tirole, J.( 2007) Reliability and Competitive Electricity Markets. RAND Journal of Economics 38: 60-84

Kahneman, D, and Tversky, A. (1979). Prospect Theory: An Analysis of Decision under Risk. Econometrica 47: 263-291.

Koomey, J.G. and Sanstad, A.H. (1994) Technical evidence for assessing the performance of markets affecting energy efficiency. Energy Policy 22: 826-832.

Laibson, D. (1997) Golden Eggs and Hyperbolic Discounting. Quarterly Journal of Economics 62: 443-77.

Langniss, O. and Praetorius, B. (2006) How much market do market-based instruments create? An analysis for the case of "white" certificates. Energy Policy 34: 200-211.

Lijesen, M.G. (2007) The real-time price elasticity of electricity. Energy Economics 29: 249258.

Linares, P., Pérez-Arriaga, I. (2008) Promoting investment in low-carbon energy technologies. European Review of Energy Markets, in press.

Loughran, D.S. and Kulick, J. (2004) Demand-side management and energy efficiency in the United States. Energy Journal 25: 19-43.

Lovins, A.B. (1994) Apples, oranges and horned toads: Is the Joskow \& Marron critique of electric efficiency costs valid? The Electricity Journal 7: 29-49.

Madlener, R. (1996) Econometric analysis of residential energy demand: a survey. Journal of Energy Literature 2: 3-32. 
McKinsey (2007) Curbing global energy demand growth: The energy productivity opportunity, McKinsey Global Institute.

Medlock, K.B. (2004) Economics of energy demand. Encyclopedia of Energy 2: 65-78.

Metcalf, G.E. and Hassett, K.A. (1999) Measuring the energy savings from home improvement investments: evidence from monthly billing data. Review of Economics and Statistics 81: 516528.

Metcalf, G.E. (1994) Economics and rational conservation policy. Energy Policy 22: 819-825.

Metcalf, G.E. (2006) Energy efficiency overview paper. Pew Center/NCEP 10-50 Workshop.

Metcalf, G.E. (2008) An empirical analysis of energy intensity and its determinants at the state level. Energy Journal 29: 1-26.

Mizobuchi, K. (2008) An empirical study on the rebound effect considering capital costs. Energy Economics 30: 2486-2516.

Mundaca, L. (2007) Transaction costs of Tradable White Certificate schemes: The Energy Efficiency Commitment as case study. Energy Policy 35: 4140-4354.

Munns, D. (2008) Modeling new approaches for electric energy efficiency. The Electricity Journal 21: 20-16.

Murtishaw, S., Sathaye, J. (2006) Quantifying the effect of the principal-agent problem on US residential energy use. LBNL-59773 Rev.

Nadel, S. (2002) Appliance and equipment efficiency standards. Annual Review of Energy and the Environment 27: 159-192.

Newell, R.G., Jaffe, A.B. and Stavins, R.N. (1999) The induced innovation hypothesis and energy-saving technological change. Quarterly Journal of Economics 114: 941-975.

Pavan, M. (2008) Tradable energy efficiency certificates: the Italian experience. Energy Efficiency 1: 257-266.

Perrels, A. (2008) Market imperfections and economic efficiency of white certificate systems. Energy Efficiency 1: 349-371.

Reiss, P.C. and White, M.W. (2005) Household electricity demand, revisited. The Review of Economic Studies 72: 853-883.

Reiss, P.C. and White M.W. (2008) What Changes Energy Consumption? Prices and Public Pressures. The RAND Journal of Economics 39: 636-63

Richmond, A.K. and Kaufmann, R.K. (2006) Energy prices and turning points: The relationship between income and energy use / carbon emissions. Energy Journal 27: 157-178.

Roca, J. and Alcántara, V. (2001). Energy intensity, CO_emissions and the environmental Kuznets curve. The Spanish case. Energy Policy 29: 553-556.

Sanstad, A.H. and Howarth, R.B. (1994) Normal markets, market imperfections and energy efficiency. Energy Policy 22: 811-818.

Saunders, H (1992) The Khazzom-Brookes Postulate and Neoclassical Growth. Energy Journal 13: 131-148

Schipper, L., Ting, M., Khrushch, M. and Golove, W. (1997). The evolution of carbon dioxide emissions from energy use in industrialized countries: an end-use analysis. Energy Policy 25: 651-672 
Simon, H.A. (1955) A behavioral model of rational choice. Quarterly Journal of Economics 69: 99-118.

Thaler, R.H. and Sunstein, C.R. (2008) Nudge: Improving decisions about health, wealth and happiness. New Haven: Yale University Press.

Tinbergen, J. (1952) On the Theory of Economic Policy. Amsterdam: North Holland.

Train, K. (1985) Discount rates in consumers' energy-related decisions: A review of the literature. Energy 10: 1243-1253.

Van Soest, D.P. and Bulte, E.H. (2001) Does the energy-efficiency paradox exist? Technological progress and uncertainty. Environmental and Resource Economics 18: 101112.

Vine, E. (2008) Breaking down the silos: the integration of energy efficiency, renewable energy, demand response and climate change. Energy Efficiency 1: 49-63.

Waide, P. and Buchner, B. (2008) Utility energy efficiency schemes: savings obligations and trading. Energy Efficiency 1: 297-311.

WEC (2008) Energy efficiency policies around the world: review and evaluation. World Energy Council.

Sue Wing, I. (2008) Explaining the declining energy intensity of the US economy. Resource and Energy Economics 30: 21-49.

Woods, J. (2008) What people do when they say they are conserving electricity. Energy Policy 36: 1945-1956.

Young, D. (2008) When do energy-efficient appliances generate energy savings? Some evidence from Canada. Energy Policy 36: 34-46.

Zhou, P., and Ang, B.W. (2008). Decomposition of aggregate CO2 emissions: A productiontheoretical approach. Energy Economics 30: 1054-1067.

Zografakis, N., Menegaki, A.N. and Tsagarakis, K.P. (2008) Effective education for energy efficiency. Energy Policy 36: 3216-3222. 


\section{TABLES AND FIGURES}

Figure 1. Primary energy demand and $\mathrm{CO}_{2}$ emissions in the US. 1990-2007 (base 1990)

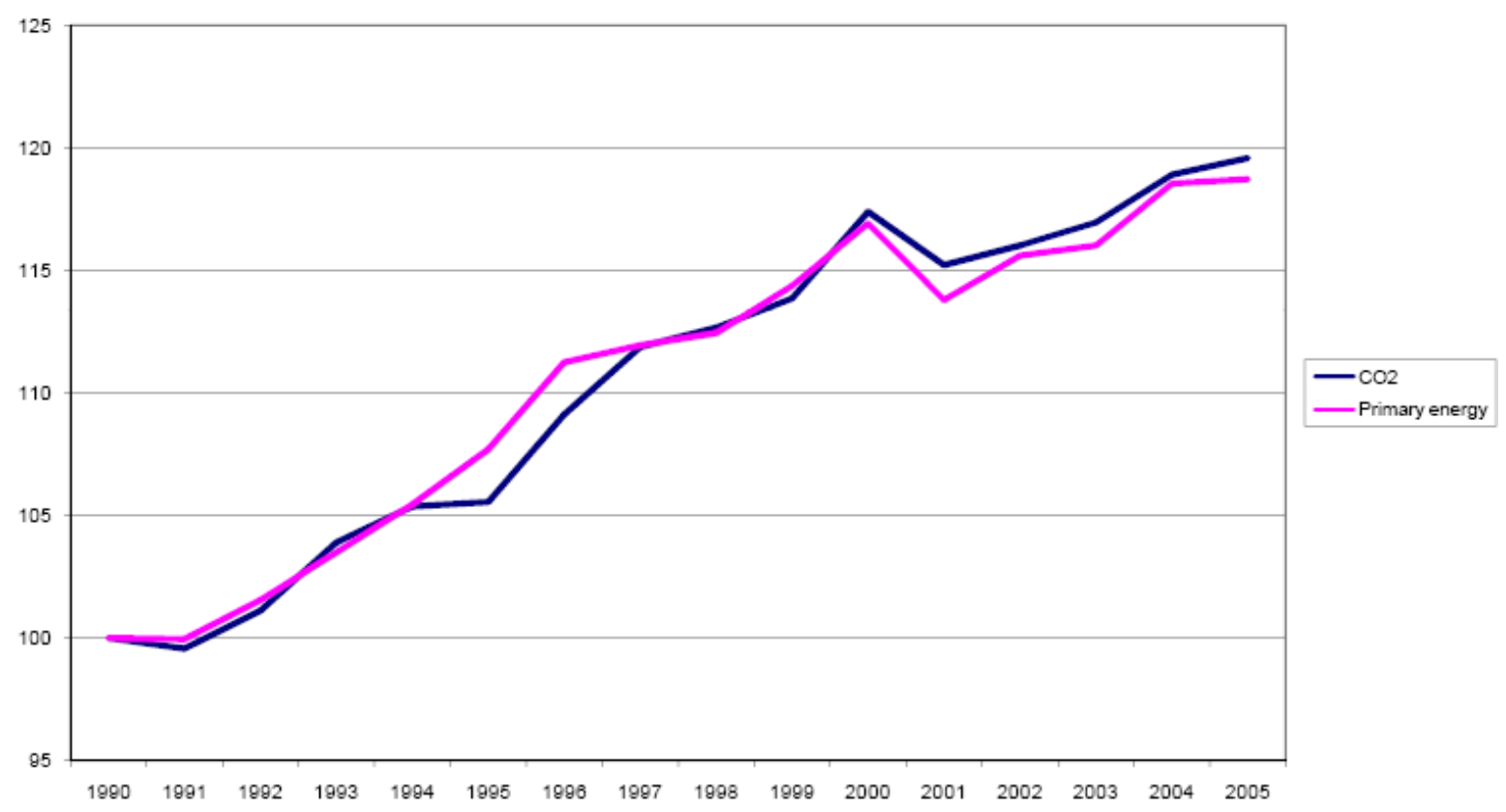

Source: Climate Analysis Indicators (World Resources Institute, Washington, DC).

Table 1. Reasons that explain the energy efficiency paradox

\begin{tabular}{|l|l|}
\hline Reason & Is it a market failure? \\
\hline Low energy prices & $\begin{array}{l}\text { Not as such. Yes if prices are not efficient (due to } \\
\text { externalities or over-subsidies) }\end{array}$ \\
\hline Hidden costs & No \\
\hline Transaction costs & Yes \\
\hline Uncertainty and irreversibility & No, unless the risk is socially diversifiable \\
\hline Information failures & Yes \\
\hline Bounded rationality & No \\
\hline Slowness of technological diffusion & Not as such, yes if there are positive externalities \\
& not accounted for \\
\hline Principal-agent problem & Yes \\
\hline Capital markets imperfections & Yes, although not significant \\
\hline Heterogeneity of consumers & No \\
\hline Divergence with social discount rates & Not necessarily \\
\hline
\end{tabular}

Source: The authors. 
Table 2. Policy instruments to address the energy efficiency paradox

\begin{tabular}{|l|l|}
\hline Low energy prices & Taxes; Real time pricing \\
\hline Hidden and transaction costs & R\&D; Institutional reform \\
\hline Uncertainty and irreversibility & Information programs \\
\hline Information failures & Information programs \\
\hline Bounded rationality & Information programs, Education, Standards \\
\hline Slowness of technological diffusion & R\&D programs; R\&D incentives \\
\hline Principal-agent problem & Information programs; Institutional reform \\
\hline Capital markets imperfections & Financing programs \\
\hline Divergence with social discount rates & Financing programs \\
\hline
\end{tabular}

Source: The authors. 